Revue

Revue de l'histoire des religions

de Ihistoire des religions

$3 \mid 2016$

Varia

Bernard ECK, La mort rouge. Homicide, guerre et souillure en Grèce ancienne

Paris, Les Belles Lettres («Collection d'Études Anciennes - Série

grecque », 145), 2012

Philippe Borgeaud

OpenEdition

Journals

Édition électronique

URL : http://journals.openedition.org/rhr/8587

DOI : $10.4000 /$ rhr.8587

ISSN : 2105-2573

Éditeur

Armand Colin

Édition imprimée

Date de publication : 1 septembre 2016

Pagination : 423-425

ISBN : 978-2-200-93061-5

ISSN : 0035-1423

Référence électronique

Philippe Borgeaud, «Bernard Ecк, La mort rouge. Homicide, guerre et souillure en Grèce ancienne ", Revue de l'histoire des religions [En ligne], 3 | 2016, mis en ligne le 06 octobre 2016, consulté le 24 septembre 2020. URL : http://journals.openedition.org/rhr/8587 ; DOI : https://doi.org/10.4000/rhr.8587

Ce document a été généré automatiquement le 24 septembre 2020

Tous droits réservés 


\title{
Bernard ECK, La mort rouge. Homicide, guerre et souillure en Grèce ancienne
}

\author{
Paris, Les Belles Lettres («Collection d'Études Anciennes - Série
}

grecque », 145), 2012

\section{Philippe Borgeaud}

\section{RÉFÉRENCE}

Bernard ECK, La mort rouge. Homicide, guerre et souillure en Grèce ancienne. Paris, Les Belles Lettres («Collection d'Études Anciennes - Série grecque », 145), 2012, 24 cm, 447 p., $35 €$ , ISBN 978-2251-32682-5.

1 Voici une étude originale qui sort, intentionnellement, des sentiers battus. Le titre aurait pu tout aussi bien en être : "phénoménologie du meurtre en Grèce ancienne ». L'objet est en effet le phonos, l'acte de tuer, et ses conséquences. Le tueur, qu'il soit guerrier ou assassin, est sujet à la souillure. La souillure déclenchée par l'acte, conçue comme métaphore de la culpabilité et du poids de la faute, est le fil rouge de cette étude qui se veut critique de plusieurs études classiques, incluant celles de Jean-Pierre Vernant sur la « belle mort » du jeune guerrier et de Robert Parker sur le miasma.

2 La perception de la souillure entraîne le besoin d'une purification. On ne s'étonnera donc pas de trouver ici de longs développements sur les Érinyes, qui sont considérées d'abord chez Eschyle, puis chez Homère. On sera surpris de certaines prises de position de l'auteur qui semble parfois recourir à des conceptions un peu désuètes, par exemple p. 33 quand il affirme péremptoirement que la légende arcadienne de Déméter Érinys est totalement étrangère, " avec son fonds indigène archaïque ", aux démons hargneux de la tragédie eschyléenne. C'est oublier que l'Arcadie, on la connaît à travers Pausanias, qui écrit au $\mathrm{II}^{\mathrm{e}} \mathrm{s}$. de notre ère et dont les sources hellénistiques sont ellesmêmes travaillées par des références classiques.

3 La question est posée du statut de la souillure dans le cadre de la guerre. Mais qu'en estil chez Homère, et plus précisément encore dans l'Iliade, ce poème de la guerre et de la 
force (Simone Weil) ? Bernard Eck insiste sur le fait que la guerre peut devenir un rite cathartique, où l'on tue pour oublier qu'on a tué. On aurait ici la marque du caractère irrationnel et proprement mystique de la mécanique sacrificielle qui fait croire que le sang se rachète par le sang (p.41). Contrairement à ce qu'ont affirmé des savants comme Raoul Lonis, Robert Parker ou Marcel Detienne, la souillure s'attache aussi au sang versé dans la guerre (p. 55). Référence est faite aux travaux de René Girard (p. 59), et un riche et curieux développement sur les rituels de lustration de l'armée nous entraîne jusque chez les Hittites, et enfin en direction du bouc émissaire de Sir James Frazer (p. 71).

4 La considération de la guerre civile, la stasis où le sang noir des citoyens exige comme rançon des folies meurtrières en retour (selon Eschyle), dicte à l'auteur des considérations qui se font en ignorance certainement intentionnelle des travaux de Nicole Loraux. L'auteur accuse (p. 105) James Redfield d'avoir un intérêt obsessionnel, et probablement d'inspiration judéo-chrétienne (p.106) pour la thématique pureté/ impureté dans son livre sur l'Iliade (La tragédie d'Hector), ce qui ne l'empêche pas d'affirmer qu'il y a "des indices probants pour soutenir que la guerre (dans l'Iliade) laisse des traces au fond de soi et que ce mal-être s'exprime parfois par un désir de se purifier, comme si l'activité guerrière était porteuse de souillures» (p.116). La conclusion sur le prétendu silence d'Homère concernant la souillure, en voulant séparer la souillure de toute coloration de culpabilité, est peu claire (p. 125-129).

5 Au centre de l'enquête de Bernard Eck, plus de cent pages sont consacrées à montrer comment l'exercice de la force qui tue transforme le guerrier, le rend fou, au point peut-être de l'identifier au dieu meurtrier lui-même, Arès miaiphonos («souillé par le meurtre »). À ce sujet, l'auteur évoque le dossier des bersekir de la tradition nordique, qui avaient fasciné les historiens des religions allemands de l'époque hitlérienne, et sur lesquels Georges Dumézil avait écrit quelques lignes remarquables dans son Horace et les Curiaces (Paris, Gallimard, 1942), dans un chapitre consacré, précisément, au furor guerrier, et où il est question, aussi, de l'Iliade (en particulier p. 16-23). Bernard Eck, curieusement, ne cite pas Dumézil.

6 Les pages consacrées à l'Iliade ont aussi pour intention de montrer que le guerrier meurtrier de la plaine de Troie est bel et bien porteur de souillure, alors qu'Homère semble ignorer la souillure déclenchée par l'homicide. La démonstration, ici, repose en partie sur les sentiments personnels du chercheur, qui n'hésite pas à recourir à des comparaisons modernes pour étayer sa thèse, et à extrapoler de l'Iliade à la Grèce classique... « Il me semble donc, écrit-il (en conclusion, p. 390), qu'il faut reconnaître, sur la foi de sources, que les Grecs ressentaient, en tuant à la guerre, non pas peut-être une culpabilité, mais un mal-être ébranlant leur for intérieur et exprimé sous la forme de la souillure ».

7 L'image du guerrier cannibale, et la pratique de la mutilation du cadavre de l'ennemi, sont analysées en balayant d'un revers de la main (p. 158) les belles réflexions de JeanPierre Vernant. La clé, selon Bernard Eck qui se réfère à Jacqueline de Romilly (p. 167), c'est ce que symbolise Arès, un dysfonctionnement général, un instinct de mort, inavouable et enfoui, ponctué par des intervalles de paix. Arès, dieu de l'immanence et de cette part maudite en nous, serait finalement un faux dieu (p.173). La mort rouge, qui donne son titre à l'ouvrage, intervient p. 187 comme une instance d'effroi, d'horreur face au destin qui force le guerrier homérique à plonger dans « la bouche de la guerre sanglante $»($ p. 207). 
8 Après ses considérations sur l'Iliade, et autour de l'Iliade, l'auteur aborde le droit et les rituels liés à la souillure. Il commence (p.211) avec Dracon. Le silence du texte de Dracon tel que nous le connaissons, et du commentaire qu'en donne Démosthène, sur le concept de souillure nous confronte à « un fait opaque » (p. 221) qui renverrait à une attitude mentale caractéristique des peuples premiers étudiés par Lucien Lévy-Bruhl. Les Tétralogies attribuées à Antiphon, où l'on voit le fantôme de la victime répandre la souillure en attendant la vengeance, représentent un exemple rare d'obsession d'une puissance mystique analogue «à celle qui anime en permanence la conduite de ces peuples» (p.239). Malheureusement, comme le relève l'auteur (p.242) on ne saura jamais si cette conception de la vengeance par des fantômes relève d'une foi authentique ou d'un jeu de l'esprit.

9 La loi sacrée de Sélinonte fait elle aussi l'objet d'une analyse, où l'auteur aborde l'épineux problème de la souillure apparemment rétroactive dont il faut laver les arrière grands-pères (les Tritopatores). Ceux-ci ne seraient pas à proprement parler des ancêtres, mais "l'esprit des ancêtres ", et, à ce titre, "dans la logique de la foi », ils appartiendraient non pas au passé, mais au présent de la famille. Bernard Eck aborde enfin la loi sacrée de Cyrène (p. 274), avant de revenir à Athènes, aux Lois de Platon (p. 310) et à la thématique du tyrannoctone (p. 323).

10 Les conclusions de l'auteur sont suivies d'une annexe sur l'expression de la culpabilité dans quelques récits de guerre contemporains (p. 393-410). Une bibliographie générale, un index des textes cités et un index général accompagnent cette étude. Il s'agit donc d'un ouvrage intéressant, de réflexion très personnelle, étayé d'une érudition solide mais sélective.

11 Les travaux de Jean-Pierre Vernant sur la guerre sont évidemment pris en compte, mais pas ses analyses de la personne, où sont abordées les thématiques de la honte, de la gloire et de la culpabilité (L'individu, la mort, l'amour. Soi-même et l'autre en Grèce ancienne, Paris, Gallimard, 1989, spécialement p.173-232). Il faut dire que la posture herméneutique de Bernard Eck est passablement éloignée d'une anthropologie historique héritée de l'école de Gernet.

\section{AUTEURS}

\section{PHILIPPE BORGEAUD}

Université de Genève. 